\title{
AS COTAS NAS UNIVERSIDADES PÚBLICAS DIMINUEM A QUALIDADE DOS INGRESSANTES?
}

LARA VILELA

THIAGO YUDI TACHIBANA

NAERCIO MENEZES FILHO

BRUNO KOMATSU

\section{RESUMO}

Este artigo utiliza os microdados do Exame Nacional do Ensino Médio (Enem) e do Censo da Educação Superior para, através de simulações sobre os efeitos das cotas, quantificar e qualificar estimativas do impacto causado pela política de cotas para acesso às universidades federais sobre a distribuição de notas do Enem de cotistas e não cotistas, as notas de corte e as médias de notas dos ingressantes. Os resultados mostram que a maior diversidade (de categoria administrativa do ensino médio, de renda e de raça) nas universidades federais, introduzida pelas cotas, não acarreta ingresso de alunos com notas significativamente menores quando comparado com o cenário sem cotas. Isso ocorre devido à existência de potenciais cotistas cujas notas se encontravam acima do último decil (décimo) de notas em número suficiente para preencher as vagas reservadas.

PALAVRAS-CHAVE COTAS • UNIVERSIDADES PÚBLICAS • POLÍTICAS PÚBLICAS • DESEMPENHO ESCOLAR. 


\section{¿LAS CUOTAS EN LAS UNIVERSIDADES PÚBLICAS DISMINUYEN LA CALIDAD DE LOS INGRESANTES?}

RESUMEN

Este artículo utiliza los microdatos del Examen Nacional de la Enseñanza Media (Enem) y del Censo de Educación Superior para, a través de simulaciones sobre los efectos de las cuotas, cuantificar y calificar estimaciones del impacto causado por la política de cuotas para acceso a las universidades federales sobre la distribución de notas del Enem de cuotistas y no cuotistas, las notas de corte y los promedios de notas de los ingresantes. Los resultados muestran que la mayor diversidad (de categoría administrativa de la enseñanza media, de renta y de raza) en las universidades federales, introducida por las cuotas, no acarrea ingreso de alumnos con notas significativamente menores cuando es comparado con el escenario sin cuotas. Esto ocurre debido a la existencia de potenciales cuotistas cuyas notas se encontraban por encima del último decil (décimo) de billetes en número suficiente para llenar las vacantes reservadas.

PALABRAS CLAVE CUOTAS • UNIVERSIDADES PÚBLICAS • POLÍTICAS PÚBLICAS • RENDIMIENTO ESCOLAR.

\section{DO PUBLIC UNIVERSITY QUOTAS LOWER THE QUALITY OF ENTRANTS?}

ABSTRACT

This article uses microdata from the National High School Exam (Enem) and the Higher Education Census to make simulations of the effects of quotas, and quantifies and qualifies their estimated effects on the access of students to federal universities, including the distribution of Enem scores as well as the cutoff and average scores for quota and non-quota students. The results show that the greater diversity (in terms of public school, poor and minority students) in federal universities caused by the introduction of the quota system has not led to the admission of students with significantly lower scores when compared to the scenario without quotas. This is due to the existence of potential quota students whose scores are in the highest score decile in sufficient numbers to fill the reserved places.

KEYWORDS QUOTAS • PUBLIC UNIVERSITIES • PUBLIC POLICY • ACADEMIC PERFORMANCE. 


\section{INTRODUÇÃO}

Com a ampliação, nos últimos anos, do acesso à educação básica no Brasil para grande parte das classes de renda mais baixa, a demanda pelo ensino superior cresceu intensamente. Apesar do considerável crescimento das vagas universitárias, os jovens pobres e negros seguem com baixa representação entre os ingressantes na universidade pública - em geral, a mais concorrida.

Esses grupos da população, negros e pobres, que muitas vezes se misturam em um só, usualmente não dispõem de recursos para custear uma formação pré-universitária de qualidade - majoritariamente privada. Ao concluírem o ensino médio em escolas públicas, encontram-se menos preparados para competirem por uma vaga no ensino superior.

Dada essa realidade, há mais de uma década colocou-se em pauta, na sociedade brasileira, a discussão sobre as ações afirmativas no campo da educação. As ações afirmativas são atos de caráter compensatório, pois visam a corrigir desigualdades historicamente acumuladas, de forma a garantir a 
igualdade de oportunidade. ${ }^{1}$ Visam a restituir uma igualdade que foi rompida ou nunca existiu (MOEHLECKE, 2002).

O debate sobre ações afirmativas obteve maior dimensão após a introdução de cotas para negros na Universidade de Brasília (UnB) em julho de 2004. ${ }^{2} \mathrm{O}$ sistema de cotas iniciado pela UnB previa a reserva de $20 \%$ das vagas de cada curso para pessoas negras. Desde então outras instituições públicas adotaram ações afirmativas, e, em 2012, o governo federal instituiu para todas as universidades federais a Lei de Cotas - Lei n. 12.711 (BRASIL, 2012b) -, que prevê a reserva de $50 \%$ das vagas dos institutos federais de educação superior ao sistema de cotas. As vagas são destinadas aos estudantes que cursaram o ensino médio integralmente em escolas públicas, diferenciando-os a partir de um critério de renda e de cor.

A crítica mais importante a esse mecanismo de inclusão das classes menos abastadas é a de que os alunos que entram através do sistema de cotas não têm nível educacional suficiente, o que geraria queda de qualidade no ensino superior. Outra crítica presente avalia que as ações afirmativas por meio de cotas não lidam com a questão mais central: a desigualdade educacional na educação básica. Segundo Durham (2005), uma das deficiências da proposta é que ela incide apenas sobre uma das consequências da discriminação racial e da desigualdade educacional, sem que estas, em si mesmas, sejam corrigidas.

O avanço dessa política de cotas teve ampla repercussão na literatura acadêmica, com discussões históricas, culturais, jurídicas, filosóficas e pedagógicas sobre o tema (MOEHLECKE, 2002; SEGATO, 2006; GUARNIERI; MELO-SILVA, 2007). Embora haja, em alguns trabalhos, uma parte voltada à análise empírica (QUEIROZ; SANTOS, 2006), são poucos os estudos empíricos que analisam o desempenho dos cotistas.

Ferman e Assunção (2005) afirmam que há uma relação negativa entre ações afirmativas e incentivos para esforço e aquisição de habilidades, constatando que estudantes favorecidos pelas cotas, na Bahia e no Rio de Janeiro (que implementaram a política de cotas raciais em 2003), tiveram piora do desempenho no vestibular entre 2001 e 2003. Comparan-
1 Para um arcabouço teórico sobre igualdade de oportunidades, ver Barros e Mendonça (1996).

2 Três universidades já haviam introduzido ações afirmativas em 2002: Universidade Estadual do Rio de Janeiro (UERJ), Universidade Estadual do Norte Fluminense (UENF) e Universidade do Estado da Bahia (UNEB). Ver Ferman e Assunção (2005). 
3 Ou seja, comparando os indivíduos que não foram aprovados, mas que seriam caso não existisse o sistema de cotas, com os indivíduos que foram aprovados, mas que não seriam caso não existisse o sistema de cotas. do os indivíduos incluídos pelas cotas com os excluídos pelas $\operatorname{cotas}^{3}$ na UnB, Francis e Tannuri-Pianto (2012) observam que entre os incluídos há uma maior proporção de negros, assim como de indivíduos oriundos de famílias com renda baixa. Além disso, apontam que os excluídos foram aprovados em outras universidades de qualidade superior, e que provavelmente teriam melhor desempenho que os indivíduos incluídos pelas cotas caso tivessem ingressado.

Velloso (2006), por outro lado, atesta que os resultados no primeiro semestre de estudos dos aprovados na UnB, em 2004, revelaram que, no conjunto de todos os alunos, mais de um terço dos cotistas se situava na metade superior da distribuição do índice de rendimento acadêmico em seus respectivos cursos, ao lado dos melhores estudantes aprovados pelo sistema universal.

Este artigo visa a contribuir para a análise de desempenho entre cotistas e não cotistas, atentando para a diferença entre os alunos na etapa anterior ao ingresso no ensino superior: o vestibular. Pretende-se verificar o impacto da política de cotas por meio da análise das notas dos ingressantes em situações distintas: sem cotas e com diferentes modalidades de cotas. Serão realizadas simulações de aprovação potencial, considerando os indivíduos que seriam aprovados em cada modalidade de cota. Ademais, será analisada a distribuição por decis de notas dos alunos que prestaram o exame.

O trabalho está dividido em sete seções, além desta introdução. Na segunda seção, é apresentado o funcionamento da Lei de Cotas. Na seção seguinte, descreve-se o Exame Nacional do Ensino Médio (Enem), assim como as modificações pelas quais passou. Na quarta seção, discorre-se sobre a estrutura de incentivos para a realização do exame e seu impacto na escolha dos anos utilizados pelo artigo. Na quinta seção, são apresentadas a base de dados e a metodologia utilizada para realizar as simulações. Em seguida, na sexta seção, expõem-se as simulações realizadas e avaliam-se seus desdobramentos em termos de participação relativa e nota. Na sétima seção, é analisada a distribuição por decis de notas. A oitava seção conclui este trabalho. 


\section{LEI DE COTAS (LEI N. 12.711/12)}

A Lei n. 12.711 (Lei de Cotas), sancionada em 29 de agosto de 2012 , determinou a reserva de $50 \%$ das vagas das instituições federais de ensino superior para estudantes que tenham cursado integralmente o ensino médio em escolas públicas (BRASIL, 2012b). A lei foi regulamentada pelo Decreto n. 7.824/2012 e pela Portaria Normativa n. 18/2012 do Ministério da Educação (MEC). A Figura 1 apresenta a distribuição das cotas.

FIGURA 1 - Reserva de vagas de acordo com a Lei de Cotas de 2012

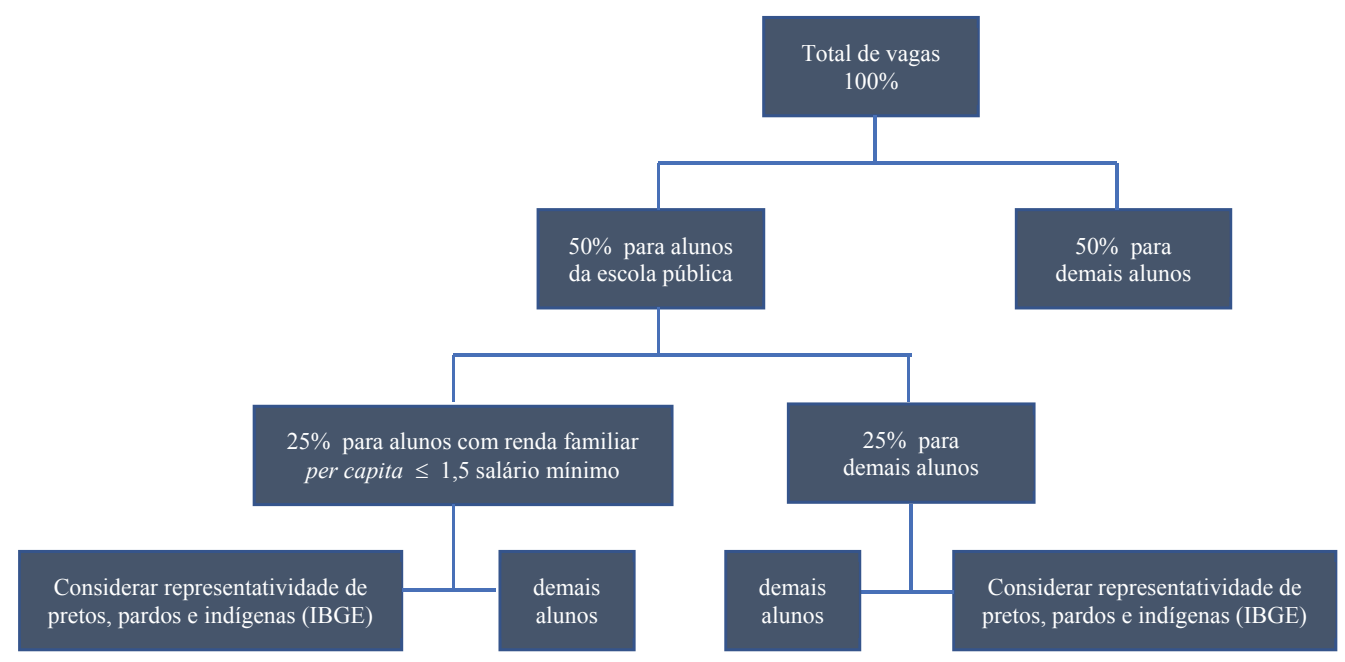

Fonte: Elaboração própria.

As cotas são divididas em quatro modalidades ${ }^{4}$ : estudantes não elegíveis (ou seja, que não estudaram em escola 4 Entende-se por modalidade de cota o grupo com uma determinada pública), estudantes de escolas públicas, estudantes com característica socioeconômica. renda familiar inferior a um salário mínimo e meio, e estudantes pretos, pardos ou indígenas. As vagas destinadas às cotas são divididas em dois: (i) metade para estudantes de escolas públicas com renda familiar bruta igual ou inferior a um salário mínimo e meio per capita; e (ii) metade para estudantes de escolas públicas com renda familiar superior a um salário mínimo e meio. Em ambos os casos, será reservado um percentual mínimo correspondente ao da soma de pretos, pardos e indígenas no estado, de acordo com o 
5 Como neste artigo realizou-se a simulação para o ano de 2011. optou-se por utilizar as informações da Pesquisa Nacional por Amostra de Domicílio do IBGE, a partir da qual é possível obter estimativas para os mesmos percentuais de representatividade para o Brasil.

6 (i) Linguagens, códigos e suas tecnologias; (ii) Ciências humanas e suas tecnologias; (iii) Ciências da natureza e suas tecnologias: (iv) Matemática e suas tecnologias. último Censo Demográfico do Instituto Brasileiro de Geografia e Estatística (IBGE). ${ }^{5}$

Foi definido um intervalo de quatro anos para que as instituições federais de ensino superior se adequassem à lei, sendo que, obrigatoriamente, $25 \%$ da reserva de vagas prevista deveriam ser implementada a cada ano.

\section{EXAME NACIONAL DO ENSINO MÉDIO}

O Exame Nacional do Ensino Médio (Enem) foi criado em 1998 pelo Instituto Nacional de Estudos e Pesquisas Educacionais (Inep) com o objetivo de avaliar o desempenho do estudante ao final da educação básica. O exame é destinado aos alunos concluintes e aos egressos do ensino médio. Embora a participação seja voluntária, o número de alunos participantes aumentou consideravelmente ao longo dos anos. Isso possibilitou a utilização do exame como ferramenta de diagnóstico do sistema educacional no país.

Até 2008, o exame era composto por uma prova objetiva com questões interdisciplinares e uma redação. Com a reformulação do Enem em 2009, o exame passou a ser composto por quatro provas objetivas, subdivididas em quatro áreas do conhecimento ${ }^{6}$, cada uma com 45 questões, e por uma redação.

A mudança principal no exame foi a adoção da Teoria de Resposta ao Item (TRI) como metodologia de correção (BRASIL, 2012c). Essa metodologia, diferentemente da utilizada antes, não se limita a contabilizar o número total de itens acertados na prova, mas qualifica o item de acordo com três parâmetros: (i) a capacidade de um item distinguir os estudantes que têm a proficiência requisitada daqueles que não a têm; (ii) o grau de dificuldade da questão; e (iii) a possibilidade de acerto ao acaso. As vantagens no uso dessa metodologia são que ela permite a comparabilidade dos resultados entre os anos e possibilita a aplicação do exame mais de uma vez ao ano.

A principal consequência da implementação dessa reformulação do Enem foi a possibilidade de utilizar o exame como forma de ingresso no ensino superior. Até 2008, o 
exame servia, majoritariamente, como complementação da nota do vestibular. A partir de 2009 , ele passou a ser utilizado como mecanismo de seleção para as instituições públicas de ensino por meio do Sistema de Seleção Unificada (Sisu). ${ }^{7}$

Respeitando a autonomia das universidades, a utilização dos resultados do Enem para acesso ao ensino superior pode ocorrer como fase única de seleção ou combinada com seus processos seletivos próprios. Há quatro possibilidades de utilização do Enem: (i) como fase única, com o sistema de seleção unificada, informatizada e on-line; (ii) como primeira fase; (iii) combinado com o vestibular da instituição; e (iv) como fase única para as vagas remanescentes do vestibular.

Adicionalmente, o Enem passou a oferecer a possibilidade de certificação do ensino médio para indivíduos maiores de 18 anos que ainda não terminaram a escolarização básica. Além disso, o exame é exigido para o acesso a programas oferecidos pelo Governo Federal, tais como o Programa Universidade para Todos (Prouni) e o Financiamento ao Estudante do Ensino Superior (Fies).

\section{ESCOLHA DOS ANOS E INCENTIVOS PARA REALIZAR O EXAME}

Desde a criação do exame, houve dois eventos importantes que alteraram a estrutura de incentivos dos alunos para realizarem a prova: (i) a reformulação do Enem em 2009; e (ii) a Lei de Cotas de 2012.

O efeito positivo da reformulação do Enem sobre os incentivos dos alunos pode ser dividido em duas partes. Uma primeira, mais direta, resume-se à possibilidade de utilização do exame como forma de ingresso no ensino superior. A segunda, por sua vez, considera a ampliação das possibilidades de acesso a esse nível de ensino. Antes da reformulação, as instituições ministravam seus próprios processos seletivos, usualmente através de um exame de vestibular. Em geral, esses exames eram aplicados no mesmo município da instituição, e alunos não residentes - especialmente aqueles de outras unidades federativas - deparavam-se com um custo de deslocamento que poderia ser elevado o suficiente para
7 Trata-se de um sistema informatizado, gerenciado pelo Ministério da Educação, por meio do qual são ofertadas vagas em cursos de graduação disponibilizadas pelas instituições públicas de ensino superior dele participantes. 
8 Note que isso não implica necessariamente, que esses alunos não se deslocariam para cursar o ensino superior caso sua aprovação fosse garantida.

9 A introdução das cotas possivelmente não serviu de desestímulo aos indivíduos não contemplados; ao contrário, deve ter estimulado seu esforço, tendo em vista a redução das vagas disputadas. que eles não se inscrevessem nesses processos seletivos, ${ }^{8}$ reduzindo suas possibilidades de ingresso no ensino superior. O caráter unificado do Enem pós-reformulação ampliou essas possibilidades, visto que o exame é realizado em todas as unidades federativas do país.

A alteração promovida pela promulgação da Lei de Cotas, em 2012, teve impactos nos incentivos dos indivíduos contemplados pela política. ${ }^{9}$ Com a reserva de vagas, criou-se uma situação em que as possibilidades de acesso ao ensino superior, antes percebidas como fora de alcance pelos elegíveis às cotas, tornam-se alcançáveis (FRYER; LOURY, 2005).

Esses dois eventos provavelmente impactaram a composição dos participantes do Enem. É razoável supor que, além disso, também impactaram o esforço desses alunos, haja vista o caráter competitivo de exames do tipo vestibular. Assim, dependendo do ano que se escolha analisar, haverá diferenças na estrutura de incentivos, bem como na composição dos alunos que realizam o Enem.

Optou-se, neste artigo, por utilizar os dados do Enem de 2011. Pelo fato de serem posteriores à mudança de 2009, os dados do exame desse ano já estão sujeitos aos incentivos criados pela possibilidade de uso do seu resultado para o ingresso nas universidades federais. Ademais, por serem anteriores à Lei de Cotas, os dados desse ano não são afetados pelas mudanças de incentivos decorrentes dela, ou seja, ainda não há o efeito da autosseleção dos cotistas na realização do Enem sobre a distribuição de notas, de modo que foi possível realizar uma simulação dos efeitos somente das mudanças de regras de seleção e ingresso devidas à Lei de Cotas.

\section{DESCRIÇÃO DA BASE DE DADOS E METODOLOGIA}

Neste artigo, são utilizadas duas bases de dados, ambas disponibilizadas anualmente pelo Inep. A primeira é composta pelos microdados do Enem para 2011 (BRASIL, 2011b), contendo as notas e informações socioeconômicas dos alunos que fizeram o exame. A segunda é composta pelos microdados do Censo da Educação Superior para 2012 (BRASIL, 2012a) 
e contém as informações sobre o número de vagas abertas para novos ingressantes.

Adicionalmente, será realizada uma análise para os anos de 2009 e 2010, respectivamente. Como 2009 é o último ano para o qual é possível realizar uma análise desagregada por curso, optou-se por incluí-lo. ${ }^{10}$ Para que a análise não se torne desnecessariamente extensa, somente duas áreas serão examinadas, a de Educação e a de Ciências Biológicas e da Saúde, que representam extremos opostos em relação à concorrência por vagas.

Os alunos ${ }^{11}$ considerados na análise foram separados por Unidade da Federação. Assumiu-se que todos os alunos de determinado estado tinham interesse em ingressar na principal universidade federal desse estado. ${ }^{12}$ Não foi incluído o estado de São Paulo por haver universidades estaduais ao menos tão procuradas quanto suas federais - a Universidade de São Paulo (USP), a Universidade Estadual de Campinas (Unicamp) e a Universidade Estadual Paulista "Júlio de Mesquita Filho" (Unesp).

Analisaram-se apenas os dados dos alunos que poderiam ingressar no ensino superior. Para que os resultados fossem comparáveis em todas as situações analisadas, foram utilizados somente os dados dos alunos que responderam às questões que permitissem identificar: (i) sua cor; (ii) sua renda familiar; (iii) o número de habitantes em sua casa (para obter a renda familiar per capita); e (iv) em que escola cursou o ensino médio. ${ }^{13}$

Como a renda familiar é dividida por faixa salarial no questionário socioeconômico, para a obtenção da renda familiar per capita dividiu-se a média dessa faixa pelo número de habitantes da casa. Por exemplo, um aluno com uma renda familiar de 2 a 5 salários mínimos e com cinco habitantes em sua casa teria uma renda familiar per capita correspondente a 0,7 salários mínimos (3,5 s.m./5 pessoas).

\section{SIMULAÇÕES}

As simulações realizadas foram desagregadas por universidade federal. Serão apresentados os resultados do estado mais populoso - segundo estimativas do IBGE para 2013 - de cada
10 Para realizar a correspondência entre candidatos e vagas por área, utilizou-se uma variável de intenção de carreira profissional, que é separada por áreas de atuação profissional razoavelmente próximas às grandes áreas do conhecimento (Q220).

\section{Para fins de notação, o termo aluno será utilizado para denotar o indivíduo que prestou a prova do} Enem.

12 Como exemplo, todos os inscritos do estado do Rio de Janeiro foram alocados como interessados em cursar a Universidade Federal do Rio de Janeiro (UFRJ).

13 Respectivamente, as variáveis TP_COR_RACA, Q4, Q1 e Q33. 
14 Utilizando microdados da Pnad 2011 (BRASIL, 2011a) uma das cinco grandes regiões do Brasil: Goiás (Centro-Oeste), Bahia (Nordeste), Pará (Norte), Minas Gerais (Sudeste) e Rio Grande do Sul (Sul).

As simulações utilizaram as regras da Lei de Cotas. Consideraram-se quatro categorias, decorrentes da inclusão gradativa das modalidades de cotas (como descrito na Figura 1): (i) sem cotas; (ii) incluindo a cota de $50 \%$ para escola pública; (iii) incluindo a cota de $25 \%$ para renda familiar per capita menor ou igual a um salário mínimo e meio; (iv) incluindo, por fim, cota da porcentagem de pretos, pardos e indígenas por unidade federativa (UF). ${ }^{14}$

Para cada uma das quatro categorias, analisaram-se estatísticas sobre os alunos que seriam aprovados nas universidades, dado o número de vagas total. Comparou-se o percentual de participação dos três grupos contemplados pelas cotas: (i) autodeclarados pretos, pardos e indígenas; (ii) com renda familiar bruta per capita menor ou igual a um salário mínimo e meio; e (iii) os que estudaram integralmente em escola pública no ensino médio. Além disso, a nota mínima e a nota média foram comparadas.

Para obter a distribuição dos aprovados pela simulação, os alunos foram ordenados de acordo com suas notas. Não foram computados, para efeito do preenchimento das vagas reservadas, os alunos elegíveis a qualquer modalidade de cota que fossem aprovados dentro do número de vagas oferecido para a ampla concorrência. Ou seja, metade das vagas foi destinada aos alunos com notas mais altas independentemente da elegibilidade para o sistema de cotas, e a outra metade foi destinada aos candidatos elegíveis para o sistema de cotas. A nota atribuída a cada aluno foi a soma das notas na prova objetiva e na redação.

\section{DISTRIBUIÇÃO POR DÉCIMOS DE NOTA}

Além das simulações, foi realizada uma análise da distribuição dos alunos por grupos de tamanhos iguais definidos pelos decis de nota (esses grupos são chamados de décimos). Com as informações das notas e o número de alunos em cada décimo, seria possível identificar em quais décimos estariam os alunos que seriam aprovados na simulação. 
TABELA 1 - Número de participantes do Enem 2011 nos cinco estados escolhidos para o estudo

\begin{tabular}{l|c|c|c|c|c}
\hline $\begin{array}{c}\text { PARTICIPANTES DO } \\
\text { ENEM 2011 }\end{array}$ & PA & BA & MG & RS & GO \\
\hline Total de inscritos & 208.950 & 355.629 & 510.100 & 251.917 & 125.286 \\
\hline $\begin{array}{c}\text { Total excluindo-se os } \\
\text { candidatos ausentes }\end{array}$ & 159.417 & 243.841 & 377.916 & 194.490 & 90.882 \\
\hline
\end{tabular}

Fonte: Elaboração própria, com dados do Inep/MEC (BRASIL, 2011b).

Foram considerados apenas os alunos que compareceram a pelo menos uma das provas. A Tabela 1 apresenta as alterações na amostra de 2011, decorrentes da retirada dos ausentes. Apesar de parecer desnecessária, a utilização desses alunos na amostra distorceria a distribuição das notas, tendo em vista que os ausentes obtêm nota zero.

\section{ANÁLISE DAS SIMULAÇÕES}

A seguir, serão apresentadas, para o ano de 2011, as simulações por universidade federal (Universidade Federal de Goiás, Universidade Federal da Bahia, Universidade Federal do Pará, Universidade Federal de Minas Gerais e Universidade Federal do Rio Grande do Sul). As simulações realizadas para 2011 utilizaram, como medida de nota, a média simples entre as notas de todas as provas, aplicando pesos iguais. Para simplificar a descrição, a seguinte notação será adotada: pretos, pardos e indígenas serão denominados PPI; estudantes com ensino médio integralmente feito em escola pública serão denominados EP; e indivíduos com renda familiar bruta per capita menor ou igual a um salário mínimo e meio serão denominados pobres. 


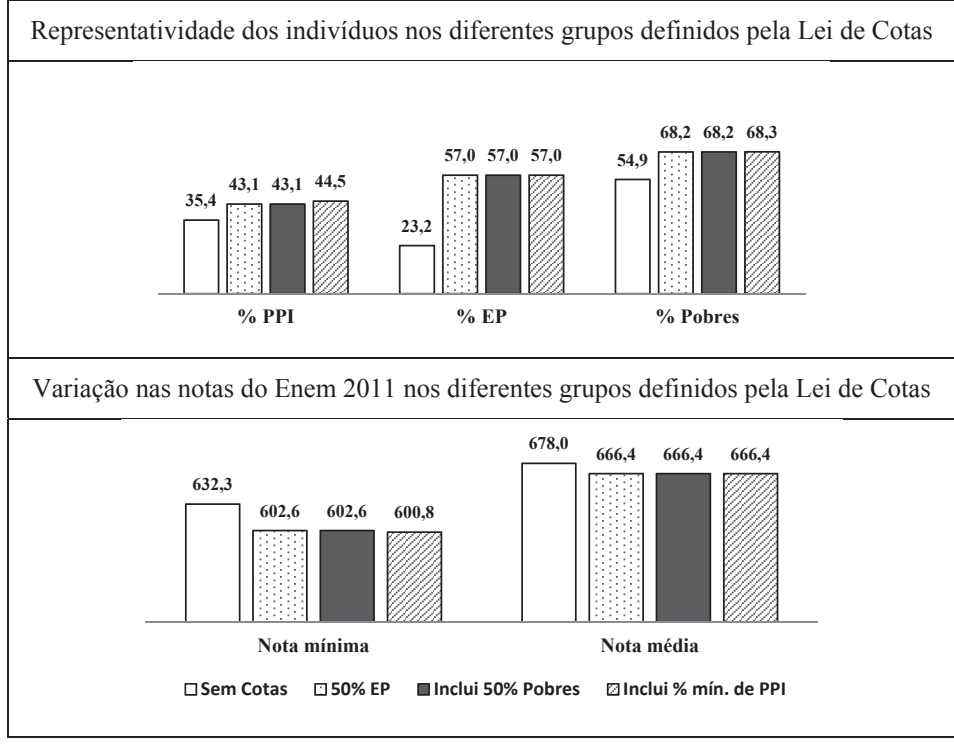

Fonte: Elaboração própria, com dados do Inep/MEC (BRASIL, 2011b).

Como é possível observar na Figura 2, no caso da Universidade Federal de Goiás, a inclusão de qualquer uma das três modalidades de cotas eleva o percentual de participação dos PPI, dos EP e dos pobres. A alteração inicial, com a cota geral para EP, gera as maiores mudanças nos percentuais de cada grupo. Entre EP e pobres, os percentuais não se alteram com nenhuma das modificações subsequentes. Esse resultado indica que os indivíduos do EP e pobres que entrariam na universidade com as cotas específicas para esses grupos já se encontram abrangidos desde o início pela regra geral para o EP.

Dentre as variações devidas à cota para EP, as mais significativas ocorrem para o próprio grupo EP, com uma elevação na participação desse grupo de mais de $100 \%$. Por outro lado, observa-se também que a participação dos PPI e dos pobres varia comparativamente pouco com a inclusão das cotas de qualquer modalidade. No caso da cota para PPI, ela altera de forma significativa somente a proporção do grupo correspondente.

Em contraste com as mudanças de composição dos entrantes, a inclusão de todas as modalidades de cotas não tem 
impactos significativos sobre a nota média - de 11,6 pontos (queda de 1,7\%). Isso ocorre apesar da redução de 31,5 pontos (queda de 5,0\%) na nota mínima.

FIGURA 3 - Simulações para a Universidade Federal da Bahia

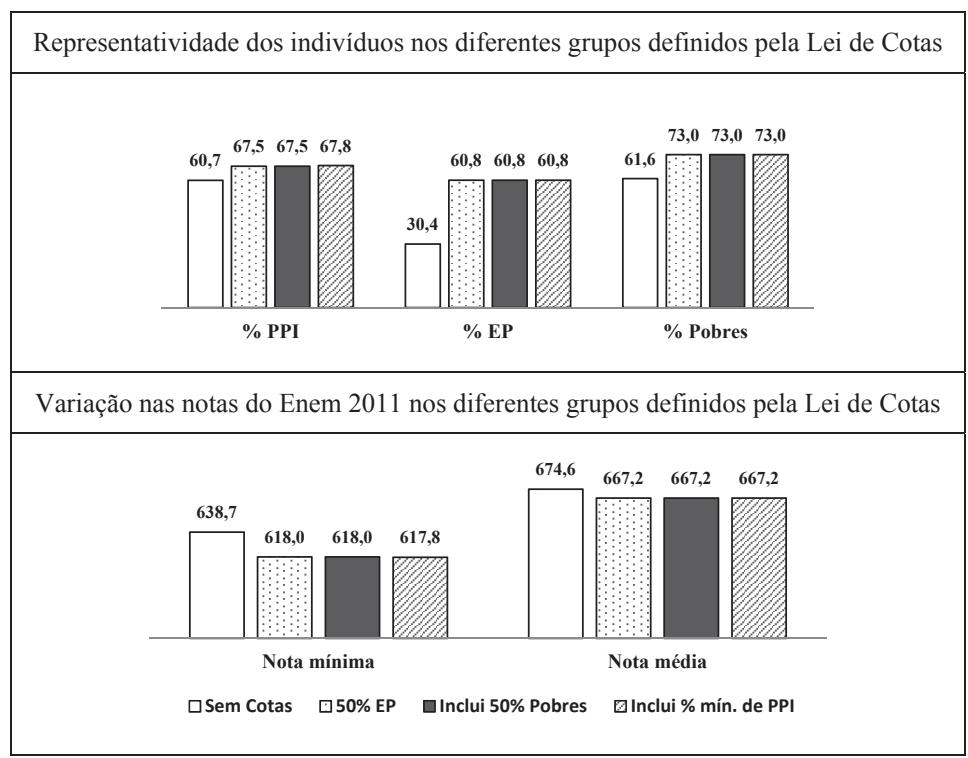

Fonte: Elaboração própria, com dados do Inep/MEC (BRASIL, 2011b).

Como se nota pela Figura 3, no caso da Universidade Federal da Bahia, a participação dos PPI e dos pobres já era elevada antes da inclusão de cotas. Para qualquer modalidade de cota incluída, a participação desses grupos fica ainda mais elevada. Como no caso do Centro-Oeste, a mudança mais significativa ocorre com a cota para os EP, com uma elevação de 30 pontos percentuais (pp) na participação, fazendo dobrar a participação desse grupo. Quando simulou-se a implementação das cotas para pobres e PPI, não foram verificadas mudanças. De fato, nesse caso, a regra para a cota de EP cobre quase inteiramente os indivíduos que seriam abrangidos pelas demais cotas.

A inclusão das três modalidades de cotas, nesse caso, também não tem impactos significativos sobre a nota média, cuja redução seria de 7,4 pontos (queda de $1,1 \%$ ). A redução da nota mínima é menos significativa na Bahia - 21 pontos (queda de 3,3\%). 
Como se observa na Figura 4, que retrata as simulações referentes à Universidade Federal do Pará, mais uma vez a participação dos PPI, dos EP e dos pobres já era relativamente elevada sem a inclusão de cotas - sendo até maior do que na Bahia. Provavelmente por esse motivo, os impactos na participação decorrentes da inclusão de cotas são inferiores aos das UFs anteriores. A variação mais significativa observada ocorre novamente para o EP, com uma elevação de 25 pp na participação desse grupo.

FIGURA 4 - Simulações para a Universidade Federal do Pará

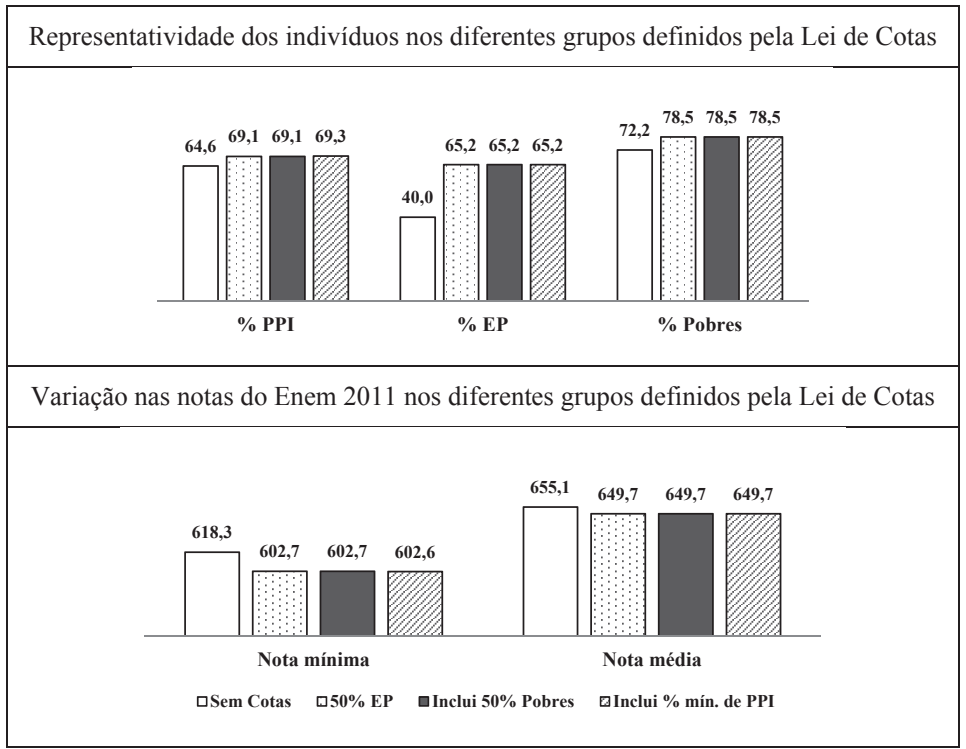

Fonte: Elaboração própria, com dados do Inep/MEC (BRASIL, 2011b).

A nota média permanece praticamente constante, com uma redução pequena no caso da cota de $\mathrm{EP}$ - de 5,4 pontos (queda de $0,8 \%$ ). Para essa mesma cota, a nota mínima sofre sua maior alteração - apenas 16 pontos (queda de 2,5\%).

A análise da Figura 5 indica que para Minas Gerais, diferentemente do Pará e da Bahia, o percentual de participação dos PPI e dos EP não era tão elevado na situação sem cotas. Assim, o impacto da inclusão de cotas na participação é significativo. O maior aumento observado no percentual de participação é para o EP, com uma elevação de quase três vezes na participação desse grupo. As cotas para PPI afetam 
a participação somente desse grupo de forma relevante, com um impacto adicional de 3,4 pp.

Os impactos sobre a nota média novamente não são elevados - de 11 pontos (queda de 1,5\%). A alteração na nota mínima é consideravelmente maior - variação de 34 pontos (queda de $4,8 \%$ ).

FIGURA 5 - Simulações para a Universidade Federal de Minas Gerais Representatividade dos indivíduos nos diferentes grupos definidos pela Lei de Cotas

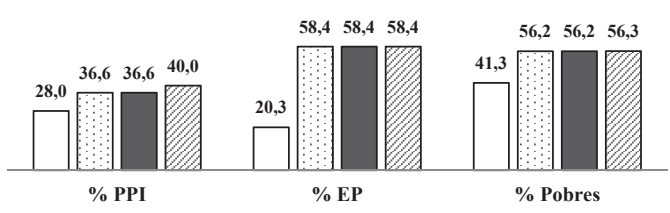

Variação nas notas do Enem 2011 nos diferentes grupos definidos pela Lei de Cotas

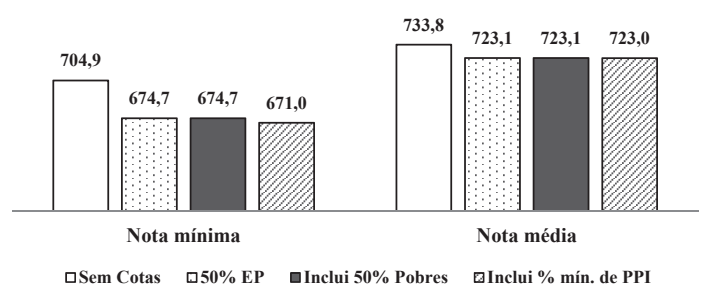

Fonte: Elaboração própria, com dados do Inep/MEC (BRASIL, 2011b).

Para a Universidade Federal do Rio Grande do Sul, como é possível observar na Figura 6, existe uma diferença notável de participação entre os diferentes grupos contemplados pelas cotas. Na situação sem cotas, a participação dos EP e dos pobres é relativamente elevada, mas a participação dos PPI é significativamente baixa. Isso ocorre, muito provavelmente, pois o Rio Grande do Sul não tem uma participação elevada de PPI em sua população. Assim, embora haja impactos relevantes com a inclusão das cotas de EP (29 pp na participação desse grupo), a maior variação observada para os PPI ocorre para a cota destinada a esse grupo, com uma elevação de 5,9 pp (103\%) em sua participação. 
FIGURA 6 - Simulações para a Universidade Federal do Rio Grande do Sul

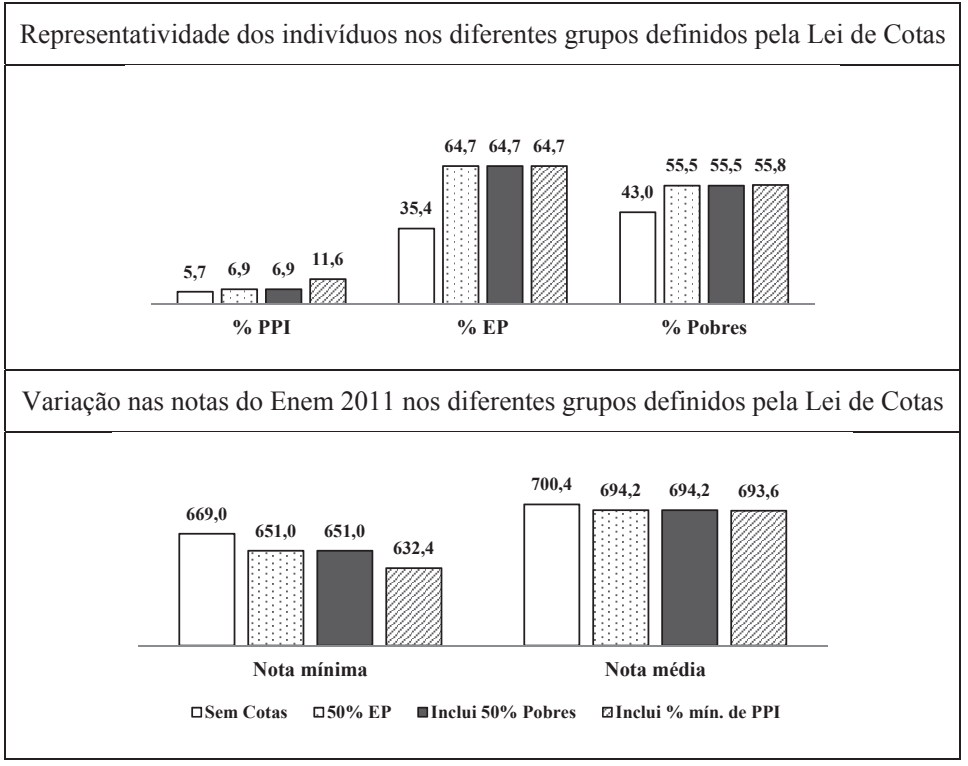

Fonte: Elaboração própria, com dados do Inep/MEC (BRASIL, 2011b).

Para as cotas destinadas aos estudantes de escola pública e para os pobres, as notas média e mínima apresentam uma redução de 6,2 pontos $(0,9 \%)$ e 18 pontos $(2,7 \%)$, respectivamente. Entretanto, para a cota destinada aos PPI, observa-se uma redução maior da nota mínima, com uma redução adicional de 18,5 pontos (que representam $2,8 \%$ da nota mínima no cenário sem cotas). No total, portanto, a nota mínima foi reduzida em 36,5 pontos $(5,5 \%)$ entre o cenário sem cotas e aquele com as cotas para PPI.

As simulações foram repetidas com os dados de 2009 e verificou-se que os resultados gerais obtidos para o ano de 2011 no geral se mantêm. Realizou-se, adicionalmente, para os dados de 2009, a simulação com a desagregação das áreas de conhecimento, para as áreas de Educação e de Ciências Biológicas e da Saúde. Em relação à área de Educação, os percentuais de EP, pobres e PPI são bastante elevados já sem as cotas em todas as UFs. No geral, há mudanças com alguma relevância no percentual de EP (entre 3 pp no Pará e 8 pp em Minas Gerais). Em Minas Gerais, a implementação do sistema de cotas também gera um aumento de 5,5 pp na 
proporção de PPI e de 2,3 pp no percentual de pobres. Em contrapartida, a redução na nota média dos ingressantes é muito pequena (entre $-0,1 \%$ na Bahia e $-0,4 \%$ em Goiás).

A área de Ciências Biológicas e da Saúde apresenta percentuais consideravelmente menores de EP, pobres e PPI. Por esse motivo, a implementação do sistema de cotas gera aumentos muito mais significativos nos três grupos (respectivamente, de 5,4 pp, 27 pp e 9 pp no Pará, que apresenta as menores magnitudes). A nota média dos ingressantes se reduz mais do que na Educação, porém com magnitude ainda baixa (no máximo 3\%, em Goiás).

\section{DISTRIBUIÇÃO POR DÉCIMOS DE NOTA}

Esta seção busca identificar, na distribuição por décimos de nota, a localização dos alunos que seriam aprovados pela simulação. Para simplificar a descrição, a aplicação da cota destinada aos EP será denotada como EP, a aplicação gradativa das cotas destinadas aos EP e pobres como EP|Pobre e a aplicação gradativa das cotas destinadas aos EP, pobres e PPI como EP|Pobre|PPI.

\section{ESTATÍSTICAS DESCRITIVAS}

De forma a analisar adequadamente os décimos de nota, é importante compreender a participação dos indivíduos elegíveis às cotas ao longo da distribuição de notas. Os 10\% com as menores notas serão referidos como o primeiro décimo, enquanto os $10 \%$ com as maiores notas serão denotados como o último décimo de notas. 
15 Um percentual alto não deve ser confundido com elevada participação de todas as modalidades de cota. Um caso hipotético de $90 \%$ de participação de cotistas poderia ser obtido com $90 \%$ dos alunos sendo pobres, mas também sendo brancos.
TABELA 2 - Proporção de indivíduos elegíveis às cotas em cada intervalo decimal de notas do Enem 2011

\begin{tabular}{c|c|c|c|c|c|c|c|c|c|c}
\hline \multirow{2}{*}{ UF } & \multicolumn{10}{|c}{ DÉCIMOS } \\
\cline { 2 - 10 } & $\mathbf{1}^{\circ}$ & $\mathbf{2}^{\circ}$ & $\mathbf{3}^{\circ}$ & $\mathbf{4}^{\circ}$ & $\mathbf{5}^{\circ}$ & $\mathbf{6}^{\circ}$ & $\mathbf{7}^{\circ}$ & $\mathbf{8}^{\circ}$ & $\mathbf{9}^{\circ}$ & $\mathbf{1 0}^{\circ}$ \\
\hline PA & 96,0 & 94,2 & 93,1 & 91,5 & 89,9 & 88,0 & 85,0 & 80,6 & 72,3 & 50,2 \\
\hline BA & 97,5 & 96,8 & 95,6 & 95,1 & 93,7 & 92,3 & 90,4 & 86,2 & 78,6 & 49,6 \\
\hline MG & 95,7 & 94,8 & 93,4 & 92,4 & 90,7 & 88,3 & 84,9 & 78,8 & 66,9 & 39,2 \\
\hline RS & 87,4 & 87,9 & 87,7 & 87,1 & 86,4 & 85,7 & 84,0 & 80,7 & 73,6 & 51,6 \\
\hline GO & 94,8 & 92,9 & 91,8 & 89,6 & 87,9 & 85,9 & 81,7 & 76,5 & 64,3 & 31,5 \\
\hline
\end{tabular}

Fonte: Elaboração própria, com dados do Inep/MEC (BRASIL, 2011b).

A Tabela 2 apresenta a participação relativa, dentro de cada décimo de nota, dos alunos elegíveis às cotas, ou seja, daqueles que são pelo menos EP. A proporção de cotistas é elevada na maior parte dos décimos ${ }^{15}$ - estando acima de $70 \%$ até o $8^{\circ}$ décimo; verifica-se uma participação menor dos cotistas nos décimos mais altos de nota.

A desagregação por áreas de 2009 permite observar algumas diferenças em relação ao agregado. Na área de Educação, apesar de as proporções de cotistas se reduzirem nos décimos mais elevados, elas se mantêm maiores do que 80\% mesmo no último décimo. Em contraste, na área de Ciências Biológicas e da Saúde, os percentuais decrescem mais intensamente nos maiores décimos de notas, ficando o último décimo em 46\% no Pará, valores entre 30\% e 35\% na Bahia, Minas Gerais e Rio Grande do Sul, e em somente 15\% em Goiás.

A Tabela 3 apresenta a participação relativa entre os décimos de nota por modalidade contemplada pelas cotas. Analisando o caso dos não cotistas (Tabela 3a), observa-se que a maior parte desses alunos se concentra nos dois últimos décimos de nota. Na Bahia, por exemplo, 40,5\% dos alunos não cotistas estão no último décimo de nota.

Ao analisar o caso dos cotistas, verifica-se que, para todos os grupos (tabelas 3b, 3c e 3d), existe uma pequena assimetria, indicando maior participação dos cotistas nos décimos mais baixos de nota e ficando o último intervalo com as proporções que mais se afastam dos $10 \%$, que seria a porcentagem esperada no caso de uma distribuição uniforme. 
TABELA 3 - Distribuição dos grupos definidos pela Lei de Cotas em cada intervalo decimal de notas do Enem 2011, para as UFs consideradas no estudo

Tabela 3a - Proporção de indivíduos não cotistas

\begin{tabular}{c|c|c|c|c|c|c|c|c|c|c}
\hline \multirow{2}{*}{ UF } & \multicolumn{10}{|c}{ DÉCIMOS } \\
\cline { 2 - 12 } & $\mathbf{1}^{\circ}$ & $\mathbf{2}^{\circ}$ & $\mathbf{3}^{\circ}$ & $\mathbf{4}^{\circ}$ & $\mathbf{5}^{\circ}$ & $\mathbf{6}^{\circ}$ & $\mathbf{7}^{\circ}$ & $\mathbf{8}^{\circ}$ & $\mathbf{9}^{\circ}$ & $\mathbf{1 0}^{\circ}$ \\
\hline PA & 2,5 & 3,6 & 4,4 & 5,3 & 6,3 & 7,6 & 9,4 & 12,2 & 17,4 & 31,3 \\
\hline BA & 2,0 & 2,6 & 3,5 & 3,9 & 5,0 & 6,2 & 7,8 & 11,1 & 17,2 & 40,5 \\
\hline MG & 2,5 & 3,0 & 3,8 & 4,3 & 5,3 & 6,7 & 8,6 & 12,1 & 18,9 & 34,7 \\
\hline RS & 6,7 & 6,4 & 6,6 & 6,9 & 7,2 & 7,6 & 8,5 & 10,3 & 14,0 & 25,8 \\
\hline GO & 2,5 & 3,5 & 4,0 & 5,1 & 6,0 & 6,9 & 9,0 & 11,6 & 17,6 & 33,8 \\
\hline
\end{tabular}

Tabela 3b - Proporção de indivíduos oriundos da escola pública

\begin{tabular}{c|c|c|c|c|c|c|c|c|c|c}
\hline \multirow{2}{*}{ UF } & \multicolumn{10}{|c}{ DÉCIMOS } \\
\cline { 2 - 11 } & $\mathbf{1}^{\circ}$ & $\mathbf{2}^{\circ}$ & $\mathbf{3}^{\circ}$ & $\mathbf{4}^{\circ}$ & $\mathbf{5}^{\circ}$ & $\mathbf{6}^{\circ}$ & $\mathbf{7}^{\circ}$ & $\mathbf{8}^{\circ}$ & $\mathbf{9}^{\circ}$ & $\mathbf{1 0}^{\circ}$ \\
\hline PA & 11,4 & 11,2 & 11,1 & 10,9 & 10,7 & 10,5 & 10,1 & 9,6 & 8,6 & 6,0 \\
\hline BA & 11,1 & 11,1 & 10,9 & 10,9 & 10,7 & 10,5 & 10,3 & 9,8 & 9,0 & 5,7 \\
\hline MG & 11,6 & 11,5 & 11,3 & 11,2 & 11,0 & 10,7 & 10,3 & 9,6 & 8,1 & 4,8 \\
\hline RS & 10,8 & 10,8 & 10,8 & 10,7 & 10,6 & 10,6 & 10,3 & 9,9 & 9,1 & 6,3 \\
\hline GO & 11,9 & 11,7 & 11,5 & 11,2 & 11,0 & 10,8 & 10,3 & 9,6 & 8,1 & 4,0 \\
\hline
\end{tabular}

Tabela 3c - Proporção de indivíduos definidos como mais pobres

\begin{tabular}{c|c|c|c|c|c|c|c|c|c|c}
\hline \multirow{2}{*}{ UF } & \multicolumn{10}{|c}{ DÉCIMOS } \\
\cline { 2 - 11 } & $\mathbf{1}^{\circ}$ & $\mathbf{2}^{\circ}$ & $\mathbf{3}^{\circ}$ & $\mathbf{4}^{\circ}$ & $\mathbf{5}^{\circ}$ & $\mathbf{6}^{\circ}$ & $\mathbf{7}^{\circ}$ & $\mathbf{8}^{\circ}$ & $\mathbf{9}^{\circ}$ & $\mathbf{1 0}^{\circ}$ \\
\hline PA & 10,4 & 10,3 & 10,3 & 10,3 & 10,3 & 10,2 & 10,2 & 10,0 & 9,7 & 8,3 \\
\hline BA & 10,4 & 10,4 & 10,3 & 10,3 & 10,3 & 10,2 & 10,2 & 10,1 & 9,8 & 8,0 \\
\hline MG & 10,9 & 10,8 & 10,8 & 10,7 & 10,6 & 10,5 & 10,2 & 9,9 & 9,0 & 6,7 \\
\hline RS & 11,0 & 10,9 & 10,7 & 10,7 & 10,5 & 10,4 & 10,2 & 9,8 & 9,0 & 6,8 \\
\hline GO & 10,7 & 10,7 & 10,7 & 10,6 & 10,5 & 10,4 & 10,3 & 10,1 & 9,3 & 6,7 \\
\hline
\end{tabular}

Tabela 3d -Proporção de indivíduos pretos, pardos ou indígenas

\begin{tabular}{c|c|c|c|c|c|c|c|c|c|c}
\hline \multirow{2}{*}{ UF } & \multicolumn{10}{|c|}{ DÉCIMOS } \\
\cline { 2 - 11 } & $\mathbf{1}^{\circ}$ & $\mathbf{2}^{\circ}$ & $\mathbf{3}^{\circ}$ & $\mathbf{4}^{\circ}$ & $\mathbf{5}^{\circ}$ & $\mathbf{6}^{\circ}$ & $\mathbf{7}^{\circ}$ & $\mathbf{8}^{\circ}$ & $\mathbf{9}^{\circ}$ & $\mathbf{1 0}^{\circ}$ \\
\hline PA & 10,4 & 10,3 & 10,3 & 10,3 & 10,2 & 10,1 & 10,1 & 9,9 & 9,7 & 8,7 \\
\hline BA & 10,3 & 10,3 & 10,3 & 10,2 & 10,2 & 10,2 & 10,1 & 10,0 & 9,7 & 8,6 \\
\hline MG & 12,2 & 11,5 & 11,1 & 10,8 & 10,5 & 10,1 & 9,7 & 9,2 & 8,4 & 6,5 \\
\hline RS & 14,8 & 13,3 & 12,1 & 11,3 & 10,4 & 9,6 & 8,9 & 8,1 & 6,8 & 4,7 \\
\hline GO & 11,5 & 11,1 & 11,0 & 10,7 & 10,5 & 10,3 & 9,9 & 9,4 & 8,7 & 6,8 \\
\hline
\end{tabular}

Fonte: Elaboração própria, com dados do Inep/MEC (BRASIL, 2011b). 
16 É importante notar que isso poderia não ocorrer, caso o número de vagas na universidade federal fosse superior ao número de alunos no primeiro décimo de nota.
Em relação aos dados de 2009, ao realizar a análise desagregada para as áreas de Educação e de Ciências Biológicas e da Saúde, os mesmos padrões se mantêm, com pequenas diferenças. Para a área de Educação, todas as distribuições são relativamente mais uniformes em todos os casos, com percentuais mais próximos de 10\%. Para a área de Ciências Biológicas e da Saúde, as distribuições são semelhantes àquelas do total de cursos.

Assim, em uma primeira análise, evidencia-se alta concentração de alunos não cotistas nos décimos mais altos de nota, combinada com uma distribuição relativamente uniforme dos alunos cotistas entre os décimos. Na análise por áreas de conhecimento, os mesmos padrões se mantêm.

\section{ANÁLISE POR DÉCIMOS DE NOTA}

Na ausência de cotas, os alunos aprovados pela simulação são, por construção, aqueles com as melhores notas, dentro de cada unidade federativa. Assim, por estarem no topo da distribuição, deveriam pertencer ao último décimo de nota ${ }^{16}$ (ou seja, ao grupo de 10\% dos alunos com as maiores notas da distribuição). De fato, é isso o que ocorre, como mostra a Tabela 4.

Para todas as unidades federativas analisadas, o número de alunos no último décimo de nota é superior ao número de vagas na universidade. Isso comprova que, de fato, todos os aprovados na simulação, em um cenário sem cotas, seriam oriundos dos $10 \%$ com as melhores notas. 
TABELA 4 - Quantidade de vagas nas Universidades Federais em estudo e de alunos no último intervalo decimal de notas do Enem 2011

\begin{tabular}{c|c|c}
\hline UF & $\mathbf{N}^{\circ}$ DE VAGAS & $\begin{array}{c}\mathbf{N}^{\circ} \text { DE ALUNOS NO ÚLTIMO } \\
\text { INTERVALO }\end{array}$ \\
\hline PA & 8.147 & 15.464 \\
\hline BA & 8.191 & 23.487 \\
\hline MG & 6.752 & 36.539 \\
\hline RS & 5.320 & 18.729 \\
\hline GO & 5.954 & 8.795 \\
\hline
\end{tabular}

Fonte: Elaboração própria, com dados do Inep/MEC (BRASIL, 2011b).

Ao introduzir o sistema de cotas, a análise deixa de ser clara. Não é possível saber, de antemão, em que décimo se encontram os alunos aprovados pelas cotas. Retirou-se a metade inferior (ou seja, de menor nota) dos aprovados sem cotas - que são pertencentes ao último décimo, como visto na Tabela 4 - para introduzir os alunos cotistas. Esses alunos cotistas também pertencem ao último décimo?

A Tabela 5 apresenta o número de vagas reservadas para o sistema de cotas, assim como o número de alunos restantes do último décimo - isto é, tendo sido retirados aqueles que seriam aprovados em ampla concorrência - que são elegíveis para cada modalidade de cota. Sempre que o número de vagas for inferior ao número de alunos elegíveis em alguma categoria de cota, conclui-se que os potenciais aprovados por essa categoria de cota são, também, oriundos do último décimo. 
TABELA 5 - Quantidade de vagas reservadas pela Lei de Cotas nas Universidades Federais em estudo e de alunos restantes ${ }^{17}$ no último intervalo decimal de notas do Enem 2011

\begin{tabular}{c|c|c|c|c|c|c}
\hline UF & $\begin{array}{c}\text { VAGAS } \\
\text { RESERVADAS } \\
\text { (EP) }\end{array}$ & $\begin{array}{c}\text { VAGAS } \\
\text { RESERVADAS } \\
\text { (EP|POBRE) }\end{array}$ & $\begin{array}{c}\text { VAGAS } \\
\text { RESERVADAS } \\
\text { (EPIPOBRE|PPI) }\end{array}$ & $\begin{array}{c}\text { ALUNOS } \\
\text { RESTANTES } \\
10^{\circ} \text { INTERVALO } \\
\text { (EP) }\end{array}$ & $\begin{array}{c}\text { ALUNOS } \\
\text { RESTANTES } \\
\text { 10 INTERVALO } \\
\text { (EP|POBRE) }\end{array}$ & $\begin{array}{c}\text { ALUNOS } \\
\text { RESTANTES } \\
\text { 10 INTERVALO } \\
\text { (EP|POBRE|PPI) }\end{array}$ \\
\hline PA & 4.074 & 2.037 & 1.601 & 6.527 & 6.148 & 4.906 \\
\hline BA & 4.096 & 2.048 & 1.608 & 10.769 & 10.247 & 8.228 \\
\hline MG & 3.376 & 1.688 & 908 & 13.767 & 11.562 & 5.734 \\
\hline RS & 2.660 & 1.330 & 242 & 8.877 & 7.140 & 719 \\
\hline GO & 2.977 & 1.489 & 844 & 2.352 & 2.135 & 1.163 \\
\hline
\end{tabular}

Fonte: Elaboração própria, com dados do Inep/MEC (BRASIL, 2011b).

17 Desconsiderando os aprovados em ampla concorrência, ou seja, a metade superior das vagas.

18 Análogo ao caso do Rio Grande do Sul. Há 5.652 alunos EP, 5.358 alunos EP e Pobre e 3.036 alunos pobres no nono décimo, todos em número superior ao de vagas restantes (respectivamente, 2.977, 1.489 e 896).
O número de alunos no último décimo excede o número de vagas em todas as categorias de cotas em todas as UFs analisadas, exceto em Goiás. Nessa UF, há um número de vagas superior ao de alunos elegíveis no caso de cotas somente para EP. Assim, para essa UF, os alunos aprovados pela simulação com cotas são pertencentes ao último e penúltimo décimos de nota ${ }^{18}$. Nas outras duas modalidades de cotas, o número de vagas é inferior ao de alunos, o que levaria ao seu preenchimento somente por estudantes do último décimo.

Há diferença considerável entre as notas do último e do penúltimo décimos? As tabelas 6 e 7 apresentam as notas mínima, média e máxima desses décimos por UF, assim como a nota de corte simulada no cenário com cotas. Como é possível observar, analisando as notas médias, existe uma diferença considerável entre os dois mais altos décimos de nota. A maior diferença $(72,5$ pontos, ou $11 \%$ da média do último décimo) ocorre em Goiás, enquanto a menor ocorre no Rio Grande do Sul (57,5 pontos, ou 8,8\% da média do último décimo). Além disso, as notas máximas e mínimas também apresentam variação ampla entre os décimos.

A amplitude observada nas notas dos dois últimos décimos poderia sugerir que as notas dos aprovados pelo sistema de cotas e que estão no penúltimo décimo são significativamente menores do que as dos demais aprovados. Contudo, não é isso o que ocorre. Ao comparar as notas dos dois últimos décimos (Tabela 6) com as notas de corte simuladas (Tabela 7), por modalidade de cota, observa-se que, nos casos 
em que há alunos aprovados pertencentes ao penúltimo décimo de nota - como em Goiás -, a nota de corte ficou mais próxima da nota máxima do penúltimo décimo. Ou seja, esses alunos, embora pertencentes ao nono décimo, estão no topo desse grupo, com notas não muito distantes das mais baixas do último décimo. Com a modalidade EP|Pobre|PPI, a redução máxima da nota de corte ocorre no Rio Grande do Sul (-5,5\% em relação ao cenário sem cotas).

Com a introdução das cotas, os alunos aprovados, no pior dos casos, pertencem ao penúltimo décimo de nota. Nesses casos, ainda, são os alunos com as maiores notas do penúltimo décimo. Esses alunos pertencem, portanto, ao topo da distribuição de notas de cada UF. Apesar de o sistema de cotas retirar alunos com notas maiores, a diferença de notas é marginal, e há alunos pobres, negros e de escola pública no primeiro e segundo décimos com boas notas e em número suficiente para que não haja redução significativa da nota média.

TABELA 6 - Medidas descritivas das notas no Enem 2011 para os dois últimos intervalos decimais de notas em cada uma das UFs consideradas no estudo

\begin{tabular}{c|c|c|c|c}
\hline UF & DÉCIMOS & NOTA MÉDIA & NOTA MÍNIMA & NOTA MÁXIMA \\
\hline \multirow{3}{*}{ PA } & $10^{\circ}$ & 630,2 & 589,0 & 825,5 \\
\cline { 2 - 5 } & $9^{\circ}$ & 568,7 & 551,6 & 588,9 \\
\hline \multirow{2}{*}{ BA } & $10^{\circ}$ & 632,7 & 588,5 & 820,2 \\
\cline { 2 - 5 } & $9^{\circ}$ & 568,0 & 550,6 & 588,5 \\
\hline \multirow{2}{*}{ MG } & $10^{\circ}$ & 673,9 & 631,2 & 848,5 \\
\cline { 2 - 5 } & $9^{\circ}$ & 609,8 & 592,0 & 631,1 \\
\hline \multirow{3}{*}{ RS } & $10^{\circ}$ & 656,0 & 616,8 & 824,7 \\
\cline { 2 - 5 } & $9^{\circ}$ & 598,5 & 583,0 & 616,8 \\
\hline \multirow{2}{*}{ GO } & $10^{\circ}$ & 659,4 & 609,9 & 830,1 \\
\cline { 2 - 5 } & $9^{\circ}$ & 586,7 & 567,8 & 609,8 \\
\hline
\end{tabular}

Fonte: Elaboração própria, com dados do Inep/MEC (BRASIL, 2011b). 
TABELA 7 - Notas de corte simuladas para os grupos definidos pela Lei de Cotas em cada uma das UFs consideradas no estudo

\begin{tabular}{c|c|c|c|c}
\hline UF & SEM COTAS & EP & EPIPOBRE & EP|POBRE|PPI \\
\hline PA & 618,3 & 602,7 & 602,7 & 602,6 \\
\hline BA & 638,7 & 618,0 & 618,0 & 617,8 \\
\hline MG & 704,9 & 674,7 & 674,7 & 671,0 \\
\hline RS & 669,0 & 651,0 & 651,0 & 632,4 \\
\hline GO & 632,3 & 609,9 & 609,9 & 609,9 \\
\hline
\end{tabular}

Fonte: Elaboração própria, com dados do Inep/MEC (BRASIL, 2011b).

A existência de alunos cotistas com notas próximas às dos não cotistas poderia ser explicada pelo "achatamento" das notas no topo da distribuição, isto é, uma distribuição de notas muito assimétrica à esquerda. Nesse caso, os alunos no topo da distribuição teriam notas muito semelhantes entre si. Então, qualquer diferença - ou ausência de - nas notas do exame não seria representativa da qualidade do aluno, e, portanto, a manutenção da nota média observada nas simulações poderia ser decorrente da incapacidade do Enem de diferenciar adequadamente os melhores alunos.

Entretanto, não é isso que ocorre. Analisando as densidades das notas para o Brasil e por UF considerada, observa-se que o Enem permite diferenciação de notas nos décimos mais elevados de nota. Como é possível observar na Figura 7, não há nenhum "achatamento" no topo da distribuição. Ou seja, a existência de alunos cotistas com notas elevadas, próximas às dos não cotistas, não se deve a uma incapacidade do exame de diferenciar os melhores alunos adequadamente, mas ao próprio mérito de tais alunos. 


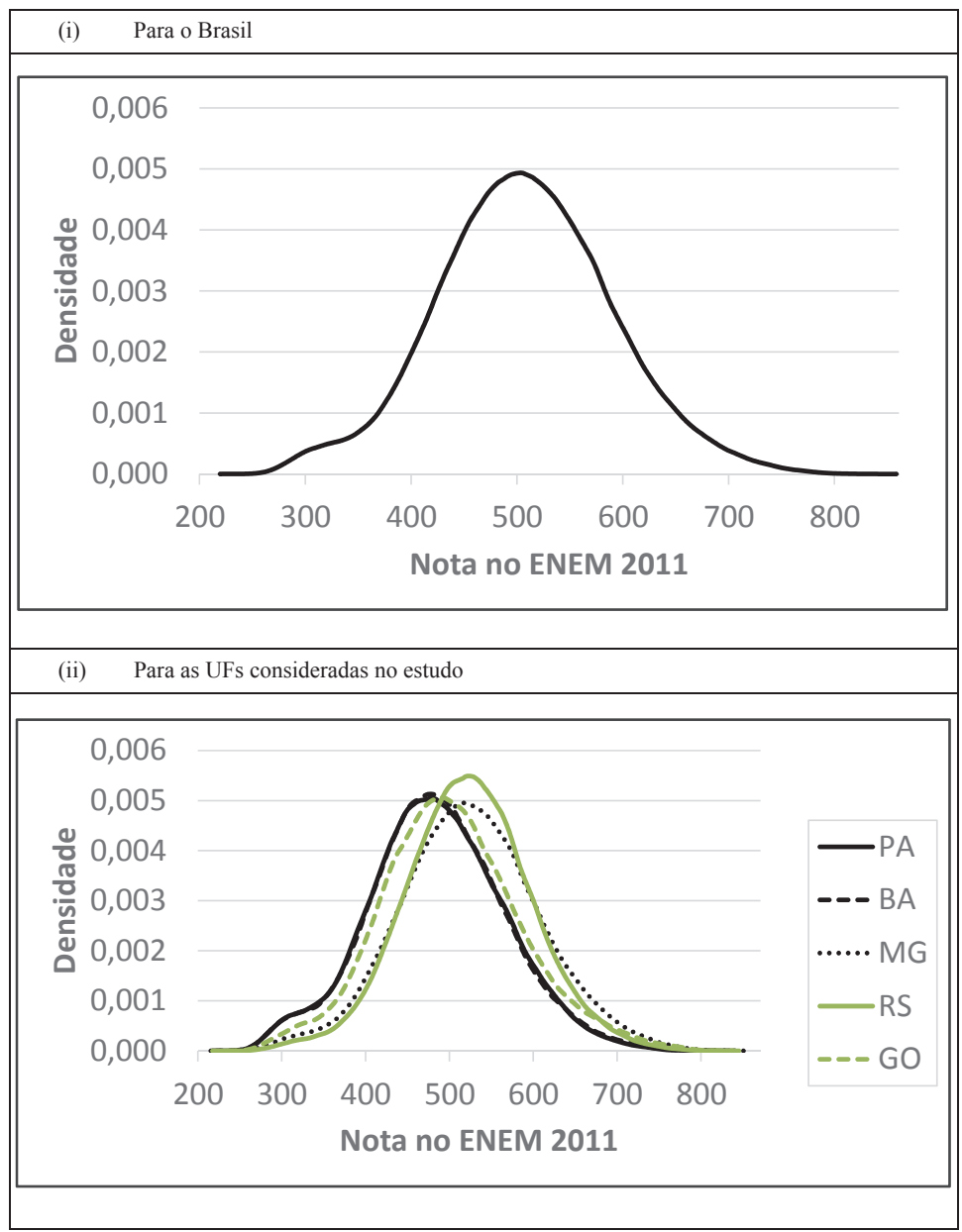

Fonte: Elaboração própria, com dados do Inep/MEC (BRASIL, 2011b).

Quando se repete a análise para a área de Ciências Biológicas e da Saúde considerando os dados de 2009, são obtidas conclusões semelhantes àquela do total de cursos. Nas tabelas 8 e 9, apresenta-se uma síntese dos resultados para essa área, bem como para a área de Educação, nos cenários sem cotas e com todas as cotas.

Na área de Ciências Biológicas e da Saúde, na ausência de cotas, as vagas seriam todas preenchidas por alunos oriundos do último décimo de notas, exceto em Goiás, onde haveria ingressantes provenientes do penúltimo décimo. Com a inclusão do sistema de cotas, na Bahia, Minas Gerais e Rio Grande do Sul haveria o preenchimento de vagas com alunos 
oriundos do último décimo nas vagas reservadas para qualquer modalidade de cotas. No Pará, somente para a modalidade EP alguns ingressantes viriam do penúltimo décimo. Em Goiás, no lugar dos alunos do último décimo, entrariam alunos do oitavo décimo na modalidade de EP, e do nono décimo, nas demais modalidades. Em consequência, como mostra a Tabela 8, a nota de corte cairia 8,5\% em Goiás com a modalidade EP|Pobre|PPI, em relação ao cenário sem cotas. Apesar de a magnitude dessa redução ser superior àquela do total de cursos em 2011, a nota média diminui somente 3\% e as mudanças nas participações dos grupos também são comparativamente maiores: aumento de 40 pp na proporção de EP, 17 pp na de pobres e 9 pp na de PPI.

TABELA 8 - Proporção de indivíduos e notas no Enem 2009 na área de Ciências Biológicas e da Saúde, considerando-se diferentes cenários decorrentes da Lei de Cotas

\begin{tabular}{c|c|c|c|c|c|c}
\hline \multirow{2}{*}{ UF } & CENÁRIOS & $\%$ PPI & $\%$ EP & $\begin{array}{c}\% \\
\text { POBRES }\end{array}$ & $\begin{array}{c}\text { NOTA DE } \\
\text { CORTE }\end{array}$ & $\begin{array}{c}\text { NOTA } \\
\text { MÉDIA }\end{array}$ \\
\hline \multirow{2}{*}{ PA } & Sem Cotas & 65,8 & 36,7 & 68,7 & 642,4 & 684,1 \\
\cline { 2 - 7 } & EP|Pobre|PPI & 71,2 & 63,6 & 77,6 & 622,9 & 677,2 \\
\hline \multirow{2}{*}{ BA } & Sem Cotas & 64,1 & 18,9 & 47,8 & 665,6 & 708,4 \\
\cline { 2 - 7 } & EP|Pobre|PPI & 71,6 & 55,5 & 63,4 & 630,7 & 694,6 \\
\hline \multirow{2}{*}{ MG } & Sem Cotas & 33,8 & 17,8 & 40,9 & 724,8 & 754,8 \\
\cline { 2 - 7 } & EP|Pobre|PPI & 44,1 & 56,4 & 57,9 & 679,5 & 740,8 \\
\hline \multirow{2}{*}{ RS } & Sem Cotas & 5,0 & 26,6 & 32,1 & 714,3 & 746,6 \\
\cline { 2 - 7 } & EP|Pobre|PPI & 12,0 & 62,8 & 45,1 & 659,6 & 734,8 \\
\hline \multirow{2}{*}{ GO } & Sem Cotas & 37,9 & 14,3 & 43,1 & 666,6 & 718,7 \\
\cline { 2 - 7 } & EP|Pobre|PPI & 47,0 & 54,1 & 60,2 & 609,6 & 697,5 \\
\hline
\end{tabular}

Fonte: Elaboração própria, com dados do Inep/MEC (BRASIL, 2009). 
TABELA 9 - Proporção de indivíduos e notas no Enem 2009 na área de Educação, considerando-se diferentes cenários decorrentes da Lei de Cotas

\begin{tabular}{c|c|c|c|c|c|c}
\hline \multirow{2}{*}{ UF } & CENÁRIOS & $\%$ PPI & $\%$ EP & $\begin{array}{c}\% \\
\text { POBRES }\end{array}$ & $\begin{array}{c}\text { NOTA DE } \\
\text { CORTE }\end{array}$ & $\begin{array}{c}\text { NOTA } \\
\text { MÉDIA }\end{array}$ \\
\hline \multirow{2}{*}{ PA } & Sem Cotas & 86,0 & 91,1 & 97,6 & 479,4 & 542,4 \\
\cline { 2 - 7 } & EPIPobre|PPI & 85,9 & 94,1 & 97,8 & 475,7 & 541,5 \\
\hline \multirow{2}{*}{ BA } & Sem Cotas & 84,5 & 90,2 & 94,4 & 545,5 & 548,7 \\
\cline { 2 - 7 } & EPIPobre|PPI & 84,8 & 93,9 & 94,6 & 543,7 & 584,2 \\
\hline \multirow{2}{*}{ MG } & Sem Cotas & 45,0 & 79,5 & 82,6 & 626,8 & 662,3 \\
\cline { 2 - 7 } & EP|Pobre|PPI & 50,5 & 87,4 & 84,9 & 620,2 & 661,1 \\
\hline \multirow{2}{*}{ RS } & Sem Cotas & 15,3 & 81,1 & 83,4 & 602,4 & 636,7 \\
\cline { 2 - 7 } & EP|Pobre|PPI & 15,9 & 89,1 & 84,0 & 596,9 & 635,6 \\
\hline \multirow{2}{*}{ GO } & Sem Cotas & 64,4 & 91,0 & 95,0 & 411,9 & 508,5 \\
\cline { 2 - 7 } & EPIPobre|PPI & 64,7 & 94,5 & 95,4 & 369,9 & 506,5 \\
\hline
\end{tabular}

Fonte: Elaboração própria, com dados do Inep/MEC (BRASIL, 2009).

Em relação à área de Educação, observa-se uma situação muito diferente. Como há relativa escassez de alunos para as vagas, no cenário sem as cotas as vagas só seriam preenchidas completamente pelos oriundos do último décimo em Minas Gerais. Nas demais UFs, os alunos viriam dos décimos mais baixos, alcançando até o terceiro décimo em Goiás. Nesse contexto de baixa concorrência, as notas de corte não se alteram de forma relevante com a introdução do sistema de cotas, como se vê na Tabela 9. Com a modalidade EP|Pobre|PPI, haveria redução de 3,6\% nessa nota em Goiás em relação ao cenário sem cotas, e diminuições de no máximo $1 \%$ nas demais UFs. As notas médias, além disso, diminuiriam no máximo 0,4\% em relação ao cenário sem cotas, novamente em Goiás.

\section{CONCLUSÃO}

Este trabalho buscou realizar um exercício empírico de aprovação potencial para analisar o desempenho dos cotistas e não cotistas na etapa que antecede o ingresso no ensino superior: o vestibular. A partir de um cenário sem cotas, 
foram realizadas simulações introduzindo sequencialmente as modalidades de cotas, de forma similar à da Lei de Cotas: (i) $50 \%$ de vagas reservadas para estudantes que cursaram o ensino médio integralmente em escola pública (EP); (ii) 50\% das cotas de EP destinadas a indivíduos com renda familiar bruta per capita menor ou igual a um salário mínimo e meio (pobres); e (iii) proporções de cotas de EP e pobres destinadas para pretos, pardos e indígenas (PPI) equivalentes às proporções de PPI na população do estado correspondente. Nas simulações, supõe-se que, em cada estado considerado na análise, todos os candidatos concorrem para a principal universidade federal daquele estado. Dessa forma, os resultados não refletem exatamente a situação de todos os estados, uma vez que em alguns deles há mais de uma universidade federal, ou universidades estaduais ou privadas, cujas vagas também podem ser objeto de competição dos candidatos.

Observa-se que os resultados foram muito similares em todas as localidades analisadas (Pará, Bahia, Minas Gerais, Rio Grande do Sul e Goiás). No geral, a inclusão da cota de EP produz as maiores alterações na composição dos estudantes que conseguem ingressar nas universidades, ampliando a participação de EP, pobres e PPI, especialmente a dos primeiros. No caso da Bahia, a proporção de EP entre os ingressantes chega a dobrar, enquanto em Minas Gerais e em Goiás ela ultrapassa o dobro. As aplicações subsequentes das cotas para pobres não apresentam efeitos relevantes, ao passo que as cotas para PPI alteram as proporções somente de PPI em Minas Gerais (de 36,5\% para 40\%) e no Rio Grande do Sul (de $7 \%$ para $11,5 \%$ ).

O resultado mais importante deste trabalho diz respeito à variação das notas. Observou-se que a inclusão das cotas não tem impactos significativos na nota média dos aprovados pela simulação em termos proporcionais (variando entre $-0,8 \%$ no Pará e -1,7\% em Goiás). Essa ausência de impacto significativo ocorre porque há alunos elegíveis para as modalidades de cotas com boas notas e em número suficiente para que não haja redução da nota média. Esses alunos, como visto, pertencem, no pior dos cenários, ao penúltimo décimo das notas, e nesses cenários têm as notas mais altas desse décimo. 
O mesmo exercício foi realizado com dados de 2009, e verificou-se que os resultados obtidos para o ano de 2011 se mantêm. Adicionalmente, implementou-se a simulação com os dados de 2009 especificamente para as áreas de Educação e de Ciências Biológicas e da Saúde, que representam áreas muito diferenciadas em relação à concorrência. Na área de Educação, as proporções de ingressantes EP, pobres e PPI já eram relativamente altas no cenário sem cotas, de forma que a implementação do sistema não gera mudanças muito grandes. Para aumentos de no máximo 8 pp entre os EP (que acontece no Rio Grande do Sul), há redução das notas médias de ingressantes de $0,2 \%$. Na área de Ciências Biológicas e da Saúde, comparativamente mais concorrida, a implementação das cotas faz com que os percentuais dos grupos de EP, pobres e PPI aumentem consideravelmente entre os ingressantes (com mínimos de respectivamente, 5,4 pp, 27 pp e 9 pp no Pará), enquanto as notas médias dos ingressantes não se alteram muito em relação ao cenário sem cotas (redução de no máximo 3\% em Goiás).

Assim, a análise dos resultados obtidos sugere que o sistema de cotas não implicaria uma redução da nota média dos ingressantes nas universidades federais. Em contrapartida, os percentuais de participação dos grupos contemplados seriam elevados para qualquer modalidade de cota, cumprindo os objetivos buscados por uma ação afirmativa desse tipo. Muito embora o vestibular não seja a proxy mais adequada para o desempenho acadêmico durante o curso de ensino superior, em face dos resultados obtidos, não parece razoável supor que a utilização de um sistema de cotas necessariamente reduziria a qualidade desse nível de ensino.

\section{REFERÊNCIAS}

BARROS, R. P.; MENDONÇA, R. Os determinantes da desigualdade no Brasil. In: INSTITUTO DE PESQUISA ECONÔMICA APLICADA. A economia brasileira em perspectiva. Rio de Janeiro: Ipea, 1996. v. 2, p. 421-474.

BRASIL. Instituto Brasileiro de Geografia e Estatística. Censo demográfico 2010. Rio de Janeiro, 2010. 
BRASIL. Instituto Brasileiro de Geografia e Estatística. Pesquisa Nacional por Amostra de Domicílios (Pnad) 2011. Rio de Janeiro: IBGE, 2011a.

BRASIL. Ministério da Educação. Instituto Nacional de Estudos e Pesquisas Educacionais Anísio Teixeira. Áreas de formação e treinamento: manual de classificação: classificação internacional Eurostat/Unesco/OCDE. Brasília, DF: Inep, 2009. Disponível em: <http://download.inep.gov.br/ download/superior/2009/Tabela_OCDE_2009.pdf $>$. Acesso em: out. 2016.

BRASIL. Ministério da Educação. Instituto Nacional de Estudos e Pesquisas Educacionais Anísio Teixeira. Microdados do Enem: 2011. Brasília, DF: Inep, 2011b.

BRASIL. Ministério da Educação. Instituto Nacional de Estudos e Pesquisas Educacionais Anísio Teixeira. Censo da Educação Superior: 2012. Brasília, DF: Inep, 2012a.

BRASIL. Ministério da Educação. Instituto Nacional de Estudos e Pesquisas Educacionais Anísio Teixeira. Lei de Cotas 2012. Brasília, DF: Inep, 2012b. Disponível em: <http://portal.mec.gov.br/cotas/docs/lei_12711_2012.pdf>. Acesso em: set. 2016.

BRASIL. Ministério da Educação. Instituto Nacional de Estudos e Pesquisas Educacionais Anísio Teixeira. Nota técnica: Teoria de Resposta ao Item. 2012c. Disponível em: <http://download.inep.gov.br/educacao_basica/enem/nota_ tecnica/2011/nota_tecnica_tri_enem_18012012.pdf>. Acesso em: Out. 2016

DURHAM, E. Desigualdade educacional e cotas para negros nas universidades. Novos Estudos Cebrap, São Paulo, v. 1, 2005. Selected Edition. Disponível em: <http://socialsciences.scielo.org/scielo.php?script=sci_ arttext\&pid=S0101-33002005000100001\&lng=en\&nrm=is $>$. Acesso em: maio 2016.

FERMAN, B.; ASSUNÇÃO, J. Affirmative action in university admissions and high school students' proficiency. Rio de Janeiro: PUC-Rio/ Departamento de Economia, 2005. (Working paper).

FRANCIS, A. M.; TANNURI-PIANTO, M. Using Brazil's Racial Continuum to Examine the Short-Term Effects of Affirmative Action in Higher Education. Journal of Human Resources, Wisconsin, v. 47, n. 3, p. 754-784, 2012.

FRYER, R. G.; LOURY, G. C. Affirmative Action and its Mythology. Journal of Economic Perspectives, Washington D.C, v. 19, n. 3, p. 147-162, 2005.

GUARNIERI, F. V.; MELO-SILVA, L. L. Ações Afirmativas na educação superior: rumos da discussão nos últimos cinco anos. Revista Psicologia e Sociedade, Florianópolis, v. 19, n. 2, p. 70-78, 2007.

MOEHLECKE, S. Ação Afirmativa: história e debates no Brasil. Cadernos de Pesquisa, São Paulo, n. 117, p. 197-217, 2002.

QUEIROZ, D. M.; SANTOS, J. T. dos. Sistema de cotas: um debate. Dos dados à manutenção de privilégios e de poder. Educação \& Sociedade, Campinas, v. 27, n. 96, p. 717-737, 2006. 
SEGATO, R. L. Cotas: por que reagimos? Revista da USP, São Paulo, n. 68, p. 76-87, 2006.

VELLOSO, J. Vestibular com cotas para negros na UnB: candidatos e aprovados nos exames (preliminar). Brasília, DF: Núcleo de Estudos para o Ensino Superior, Universidade de Brasília, 2006.

\section{LARA VILELA}

Trainee de Gestão Pública do Vetor Brasil, Recife, Pernambuco, Brasil

lara.oliveiravilela@gmail.com

\section{THIAGO YUDI TACHIBANA}

Doutorando da Escola de Economia de São Paulo (EESP) da Fundação Getúlio Vargas (FGV), São Paulo, São Paulo, Brasil thiagotachibana@gmail.com

\section{NAERCIO MENEZES FILHO}

Coordenador do Centro de Políticas Públicas (CPP) do Insper. Professor da Faculdade de Economia, Administração e Contabilidade da Universidade de São Paulo (FEA/USP), São Paulo, São Paulo, Brasil naercioamf@insper.edu.br

\section{BRUNO KOMATSU}

Assessor de Pesquisas do Centro de Políticas Públicas (CPP) do Insper. Doutorando da Faculdade de Economia, Administração e Contabilidade da Universidade de São Paulo (FEA/USP), São Paulo, São Paulo, Brasil brunokk@uol.com.br 


\section{APÊNDICE - SIMULAÇÕES PARA DESAGREGAÇÃO POR ÁREAS EM 2009}

O Censo da Educação Superior de 2010 apresenta a classificação dos cursos de acordo com um manual produzido pela Eurostat em parceria com a Organização das Nações Unidas para a Educação, a Ciência e a Cultura (Unesco) e a Organização para a Cooperação e Desenvolvimento Econômico (OCDE) (BRASIL, 2009). O manual tem como base a Classificação Internacional Padronizada da Educação (International Standard Classification of Education - Isced). A Tabela A apresenta a compatibilização realizada.

TABELA A - Compatibilização de cursos entre as bases de dados

\begin{tabular}{|c|c|}
\hline DIVISÃO ENEM (Q220) & DIVISÃO OCDE (CENSO DA EDUCAÇÃO SUPERIOR) \\
\hline Professor(a) de EF e EM & 1 Educação \\
\hline Profissão ligada às Artes & $\begin{array}{l}2 \text { Humanidades e Artes } \\
\text { - } 21 \text { Artes }\end{array}$ \\
\hline $\begin{array}{l}\text { Profissão ligada às } \\
\text { Ciências Humanas }\end{array}$ & $\begin{array}{l}2 \text { Humanidades e Artes } \\
\text { - } 22 \text { Humanidades e Letras } \\
3 \text { Ciências Sociais, Negócios e Direito }\end{array}$ \\
\hline $\begin{array}{l}\text { Profissão ligada às } \\
\text { Engenharias/Ciências } \\
\text { Tecnológicas }\end{array}$ & $\begin{array}{l}4 \text { Ciências, Matemática e Computação } \\
\text { - } 44 \text { Ciências físicas } \\
\text { - } 46 \text { Matemática e estatística } \\
\text { - } 48 \text { Computação } \\
5 \text { Engenharia, Produção e Construção } \\
6 \text { Agricultura e Veterinária } \\
\text { - } 62 \text { Agricultura, florestas e recursos pesqueiros } \\
\text { - } 623 \text { Engenharia florestal - Silvicultura }\end{array}$ \\
\hline $\begin{array}{l}\text { Profissão ligada às } \\
\text { Ciências Biológicas } \\
\text { e de Saúde }\end{array}$ & $\begin{array}{l}4 \text { Ciências, Matemática e Computação } \\
\text { - } 42 \text { Ciências da vida } \\
6 \text { Agricultura e Veterinária (Exceto 623) } \\
7 \text { Saúde e Bem-Estar Social }\end{array}$ \\
\hline
\end{tabular}

Fonte: Elaboração própria, com dados do Inep/MEC (BRASIL, 2009). 
